\section{Ética e medicina preditiva}

\section{Ethics and predictive medicine}

\begin{abstract}
Technological developments in recent times have allowed us to master genetics and this has had an impact on medicine through the creation of the field of predictive or pre-symptomatic medicine. Predictive medicine, using genetic testing produces a prognosis regarding the likelihood of an individual, in the future, developing some kind of genetic disease and aims to prevent and cure it. However, as with any kind of knowledge, the science of pre-symptomatic diagnostics, which is capable of manipulating life itself, can be used for good or for ill. For this reason, there is a need to raise the ethical questions involved. This theoretical article aims to address such issues.
\end{abstract}

Key words Technological development, Preventive medicine, Ethics
Ítalo Márcio Batista Astoni Júnior 1

Giovano de Castro lanotti 2
1 Programa de Doutoramento em Bioética. Faculdade de Medicina. Universidade do Porto. Alameda Prof. Hernâni Monteiro, 4200-

319. Porto, Portugal. E-mail: italoastoni@ig.com.br

2 Instituto Mineiro de Homeopatia. Belo Horizonte, MG, Brasil.

\section{Resumo}

A evolução tecnológica dos tempos modernos penetrou o domínio da genética e atingiu o campo da medicina, constituindo-se na chamada medicina preditiva ou pré-sintomática. A medicina preditiva, utilizando-se de testes genéticos, é a competência prognóstica quanto à possibilidade de um indivíduo vir a desenvolver, no futuro, alguma doença ligada aos genes, objetivando preveni-la e remediá-la. Entretanto, como qualquer conhecimento, a ciência do diagnóstico pré-sintomático, capaz de manipular a vida alterando a essência mesma do ser, pode produzir tanto "benefícios" quanto "maleficios", o que torna necessário problematizá-la eticamente. $O$ presente artigo, de natureza conceitual, foi escrito almejando este fim.

Palavras-chave Desenvolvimento tecnológico, Medicina preventiva, Ética 


\section{Introdução}

O avanço tecnológico dos tempos modernos chegou à esfera da biologia, sendo denominado de biotecnologia; atingiu o domínio da genética, sendo chamado de engenharia genética, e, inevitavelmente, alcançou o âmbito da saúde. ${ }^{1}$

Esse desenvolvimento, entretanto, trouxe consigo uma relevante contradição a ser resolvida, ou, pelo menos, debatida e moderada. Por um lado, tornou-se possível intervir e alterar a essência mesma do ser, através da modificação dos genes. ${ }^{2} \mathrm{O}$ sonho humano de desvendar e dominar os segredos da natureza apresentou-se mais real. ${ }^{3}$ Por outro, a manipulação da vida, por si só impactante, tem gerado delicados conflitos éticos e morais, ${ }^{1}$ fazendose imprescindível, para abordá-los, uma ética consequente e responsável. 4

É neste contexto que se insere a medicina preditiva, uma das especificações oriundas desse progresso, no campo da medicina. 5

\section{Conceituação}

A medicina preditiva é a capacidade de fazer predições quanto à possibilidade de um indivíduo vir a desenvolver alguma enfermidade de base genética, no futuro. É a mensuração, através de testes genéticos, da predisposição deste indivíduo e, talvez, de seus familiares, para tal tipo de adoecimento. ${ }^{1}$

A medicina preditiva identifica pessoas saudáveis e assintomáticas portadoras de genes mutantes ou de risco para determinadas doenças 6 objetivando preveni-las e remediá-las, ${ }^{7}$ podendo ser estendida ao terreno do diagnóstico pré-natal e ao ramo do diagnóstico embrionário pré-implantação.

A eficácia prognóstica das provas genéticas dependerá do grau de interação do gene pesquisado com a própria moléstia que origina e com o meio circundante. 1

\section{A relação entre o genótipo e o fenótipo}

O genótipo é o conjunto de genes de um indivíduo, ${ }^{8}$ permanecendo constante por toda a existência. ${ }^{1}$

$\mathrm{O}$ fenótipo diz respeito às características observáveis deste indivíduo, como, por exemplo, seu comportamento, sua aparência física e seu estado de saúde ou doença, modificando-se constantemente com o passar do tempo e registrando, assim, sua história. ${ }^{1}$

O genótipo não determina um fenótipo, e sim uma gama de fenótipos possíveis, ou seja, uma norma de reação. A norma de reação é todo o repertório de vias alternativas de desenvolvimento que podem ocorrer nos portadores de um dado genótipo, em um meio qualquer, favorável ou desfavorável, natural ou artificial. ${ }^{1}$ A esse infinito de possibilidades nomeamos biodiversidade, componente fundamental do equilíbrio existencial. Segundo Salzano, ${ }^{9}$ na biodiversidade, as diferentes formas de vida estão tão intrincadas entre si que não se devem dispensar mesmo os organismos mais simples.

Qual fenótipo se concretizará, incluindo o adoecimento, também dependerá do genótipo e do seu nível de interação com o ambiente, ${ }^{1}$ sendo essas interações complexas e de longo prazo, 10 constituindo-se, geralmente, na relação de vários genes com múltiplos determinantes ambientais. 11

\section{0 adoecimento genético}

Mutações em um único gene podem ser capazes de, "sozinhas", causarem uma doença genética. Nestes casos, o gene é dito de grande efeito, a doença é denominada monogênica e sua herança é classificada em autossômica dominante, recessiva ou ligada ao sexo. ${ }^{1}$ Geralmente, são moléstias de início tardio para as quais não existe tratamento, sendo difícil precisar a época exata em que se manifestarão. 12 Seus testes genéticos apresentam grande previsibilidade, porém, a possibilidade de modificação do risco de desenvolvimento da enfermidade é pequena. 1 Podemos citar, como exemplo, a doença de Huntington, condição neurodegenerativa, de recorrência familiar. 12

A maioria das doenças comuns do homem, entretanto, como o câncer, a diabetes, a arteriosclerose e a hipertensão arterial, são multifatoriais, originandose, como já sinalizado previamente, de uma complexa interação entre vários genes de pequeno efeito e o ambiente. ${ }^{1}$ Nestas enfermidades, chamadas poligênicas, o que se detecta é somente uma predisposição aumentada, ou seja, a presença da mutação determina um risco aumentado em relação à população geral, mas não necessariamente implica na ocorrência futura da moléstia. 12 Suas provas genéticas têm baixa previsibilidade e, consequentemente, sua utilidade clínica é ainda imprecisa, ${ }^{12}$ embora as chances de manipulação do meio para evitar o adoecimento sejam altas. ${ }^{1}$

A maior parte das doenças genéticas situa-se entre as puramente monogênicas e as claramente poligênicas. Na grande maioria das enfermidades monogênicas há influência de outros genes e de fatores ambientais, variando sua penetrância e grau de expressividade, bem como na grande maioria das 
moléstias poligênicas há alguns genes de ação mais efetiva que outros, considerados genes maiores. ${ }^{1}$

\section{Reflexões éticas associadas}

Segundo Frota-Pessoa, 13 qualquer conhecimento pode contribuir tanto para o "bem" quanto para o "mal". A medicina preditiva não é diferente, apresentando, simultaneamente, um leque imenso de "possibilidades"3 e um enorme potencial "iatrogênico", o que torna necessário problematizá-la eticamente. 1

Sua primeira pretensão é uma maior qualidade de saúde para a vida das pessoas, 14 o que repercute nas gerações futuras, possuindo, como instrumentos mais relevantes para esse fim, as alterações ambientais na maneira de viver de cada homem e a terapia gênica. Esta é definida como a manipulação intencional, direta e programada do material genético humano, dotada do poder de transformá-lo, definitivamente. 14

Dentre seus possíveis "benefícios" considerados por muitos, podemos mencionar:

- a capacidade de prevenir uma doença genética atrasando e/ou amenizando seus sintomas, ou mesmo evitando o seu aparecimento, 15 e de remediar tal enfermidade corrigindo seus genes mutantes ou de risco, avaliados como defeituosos, anormais ou imperfeitos;

- a revelação proporcionada, aos pais, do risco genético dos próprios filhos; 16

- a chance de ponderar e planejar o futuro,16 adequando os projetos vitais, quer sejam profissionais, reprodutivos ou outros, ${ }^{4}$ principalmente nas afecções monogênicas;

- a diminuição da mortalidade nas manifestações poligênicas, como o câncer, por exemplo, 16 através das modificações profiláticas necessárias à minimização do risco de desenvolvê-las. ${ }^{1}$

Dentre suas reflexões éticas passíveis de serem formuladas, destacamos:

- a insuficiência do paradigma biotecnocientífico, um cartesianismo racional-operacional, claro e distinto, em dar conta do mundo da vida; 14

- o biopoder gerado pelo paradigma biotecnocientífico, aos seus detentores, em virtude da capacidade de manipulação da vida, e o seu uso irresponsável e inconsequente; 13

- o risco de se lesar a saúde com técnicas invasivas, 11 como por exemplo, a terapia gênica, 17 bem como o perigo do seu endeusamento; 6

- a realidade de que o genoma está sujeito a múltiplos processos desestabilizadores. Um gene transferido pode mutar, mudar de posição, recombinar-se ou mesmo transferir-se para outro organismo. Estabilidade de herança e de reprodução não reside na estabilidade dos genes, sendo melhor distribuídas em todo o sistema de desenvolvimento inerente ao meio ambiente. A vida, ao contrário dos procedimentos da engenharia biológica, é irredutivelmente holística; 18

- a dificuldade de se fazer previsões, em um genoma instável, o que requer especial cuidado antes de se emitir conclusões; 18

- o fato de que entre ser portador de um gene alterado e apresentar sua respectiva doença existe uma probabilidade e não uma certeza. ${ }^{1} \mathrm{O}$ que se herda é uma fraqueza ou predisposição constitucional para um determinado tipo de adoecimento. 19 $\mathrm{Na}$ vida e na saúde, o risco nunca pode ser eliminado completamente, 14 sendo difícil compreender o seu significado. 20 É necessário perceber que nem um diagnóstico negativo é uma exclusão e nem um diagnóstico positivo é uma sentença inexorável de enfermidade. ${ }^{4}$ A cultura do medo e do terror em que vivemos deve receber seu salutar constrangimento; 18 - uma concepção genética simplificada que reduz a totalidade da vida e da saúde ao componente genômico. 14 Neste reducionismo genético, os genes, excessivamente valorizados, possuem a explicação final para a maioria, senão todas, das manifestações fenotípicas, incluindo o comportamento e a doença, com pouca ou nenhuma influência do meio; 10

- o conceito de que os traços humanos, sob a influência dos genes, são totalmente fixos em sua determinação e caracterização fenotípicas, 10 subestimando as implicações concernentes ao ambiente. $6 \mathrm{O}$ paradigma da causalidade é transferido para o genoma, 1 o que transforma o indivíduo em um prisioneiro gênico ${ }^{21}$ e desintegra a responsabilidade individual, coletiva e ambiental de cada um. ${ }^{1}$ Reedita-se, em verdade, a velha questão da liberdade humana, do seu livre-arbítrio responsável e de suas inerentes consequências versus a necessidade divina, a fatalidade da vida ou destino, ${ }^{3}$ através da intervenção ou não na natureza das coisas. ${ }^{14}$ Este determinismo genético pode impactar negativamente as decisões reprodutivas de um casal que esteja enfrentando um risco genético, induzindo-o a interromper a gravidez, ou seja, a abortar; 10

- encontrar-se ainda em um estágio inicial, o que a põe em contato com o desconhecido, com o novo, 14 e, sob certo aspecto, com o perigoso; 4

- os efeitos imponderáveis, imprevistos, logo inquietantes, irreversíveis e irreparáveis das ações interventivas no genoma humano, 14 com repercussões na coletividade e nas gerações futuras, o que transforma o tempo em uma variável ética ${ }^{4}$ e torna plausível o 
aparecimento de acidentes biológicos; 3

- os acidentes biológicos, geralmente desastrosos, que podem se constituir de novos germes patogênicos, de bactérias mutantes, de graves doenças e epidemias, ${ }^{3}$ e de quiméricas e indignas aberrações ou monstruosidades;

- a biodiversidade como fator de viabilidade 15 e de estabilidade 9 da espécie humana, devendo, pois, ser respeitada e protegida em sua individualidade e identidade. ${ }^{21}$ As anormalidades ou doenças ligadas aos genes, ao invés de serem "imperfeições" ou "inferioridades", 21 não seriam apenas diferenciações manifestas dentre uma infinidade de variantes genéticas ocultas e distribuídas em todos nós?15 Segundo Campos, ${ }^{21}$ as enfermidades não impossibilitam as pessoas de exercerem o seu papel na sociedade, que é único e imprescindível para a formação desta diversidade;

- a possibilidade de deslocamento, por parte do homem, de modificações no genoma humano justificadas no cuidado à saúde para intervenções centradas no conceito exclusivo de melhoramento artificial geral do ser e da raça, tendo por base a satisfação de caprichos 15 ou desejos imaginários, $14 \mathrm{o}$ que se define como eugenia. Na eugenia, acredita-se em "bad" genes e busca-se descartá-los ou substituílos por "good" genes, libertando a humanidade do seu mal-estar e sofrimento. 14 A seleção natural é trocada por processos mais compassivos e não menos eficientes, 19 o que ameaça a salvaguarda adaptativa da variabilidade. 22 Esta concepção, aplicada às gerações futuras, constitui-se na paternidade "ideal" ou com ressalvas, ou seja, é a procura irreal pelo filho "perfeito" com a eliminação ou exclusão dos "imperfeitos" ou mesmo o impedimento da procriação, o que interfere na liberdade e na diversidade humanas. ${ }^{21}$ Afinal, o que é o melhor e para quem? Quem o determina? Pautado em qual conhecimento ou critério? ${ }^{17}$ Em qual contexto?

- o que é o bom? O que é o ruim?15 Existem intrínseca e previamente genes "bons" ou "maus"?1 Apenas em nível do ácido desoxirribonucleico (DNA) é possível se fazer juízos de valor? ${ }^{1}$ Talvez seja necessário exercitar, em nossas impressões cotidianas, a prática da abstenção de qualquer tipo de julgamento apriorístico, com profunda aceitação das solicitações da vida;

- o que é a normalidade? É a ausência de anormalidade, uma não definição, ou é uma média da população, uma variável quantitativa e específica? Segundo Opitz, 19 o que se observa é que não há um discurso consensual em relação a este conceito, com o mesmo condicionando-se por valores do próprio ser, como os biológicos e culturais, e pela tolerância de uma sociedade para com a variabilidade estrutural ou funcional. O considerado anormal ou patológico seria, pois, uma aplicação de pedigree aos seres humanos, ${ }^{18}$ uma ideologia de felicidade, ${ }^{14}$ promotora de discriminação. ${ }^{21}$ A maioria das variações, na maioria dos traços hereditários, na maioria das pessoas, na maior parte de suas vidas, está dentro dos limites normais e merece mais atenção, ${ }^{19}$ principalmente por parte dos médicos;

- a compreensão da vida como dada e sagrada, tornando-a, pois, intocável e imanipulável em essência. Seria lícito intervir nos desígnios do criador, já presentes na intrínseca, boa e finalista ordenação da(s) natureza(s)?

- a quem pertence o genoma? Por um lado, o genoma tem características de propriedade privada, ou seja, é próprio do indivíduo, pertencendo, pois, a ele. 1 Por outro, tem características de propriedade coletiva, ou seja, é um patrimônio comum da humanidade, no qual está registrada toda nossa história como espécie e projetada a nossa potencialidade evolutiva; 1

- a autonomia sobre o genoma é plena? Em relação às células somáticas, cabe à pessoa decidir sobre o próprio genoma? Já em relação às células germinativas, a questão ultrapassa os limites do pessoal, pois qualquer intervenção nestas células pode ser transmitida aos descendentes, o que se transforma em um problema coletivo patrimonial da humanidade. 15 Todo o "bem" e todo o "mal" que for feito em nível individual pode se expandir a uma esfera coletiva maior. $4 \mathrm{O}$ convênio Europeu de Bioética proíbe a manipulação do genoma humano com vistas a modificá-lo em sua descendência, 11 com as futuras gerações tendo o direito a um patrimônio genético inalterado. $23 \mathrm{O}$ genoma comporta em si a dignidade do Homem como indivíduo singular e como espécie, devendo, pois, ser respeitado e protegido, 15 ética e juridicamente; ${ }^{2}$

- a inconveniência de se usar as informações genéticas para fins comerciais ou de patente; 15

- o direito de todo ser humano à privacidade e à confidencialidade de suas informações genéticas, $10 \mathrm{o}$ que se constitui em fator de proteção contra a discriminação e a segregação por parte de terceiros, ${ }^{21}$ principalmente no mercado de trabalho. Segundo Bergel,11 a informação gênica sobre um indivíduo deverá ser obtida ou revelada somente com a autorização do mesmo ou de seu representante legal, e qualquer exceção a este princípio requer uma forte justificativa legal e ética;

- a discriminação e a estigmatização sociais de base genética, presente nos planos de saúde e em todo o mercado de trabalho, provenientes da diminuição da privacidade e da confidencialidade das informações 
gênicas pessoais e do reducionismo e determinismo genéticos, levando à segregação e exclusão e gerando a necessidade de solidariedade, de proteção jurídica e de respeito à dignidade humana. Segundo França, ${ }^{7}$ nas doenças poligênicas, o indivíduo é marginalizado apenas pela ameaça do risco de manifestá-las. O art. 11 da Convenção Sobre os Direitos do Homem e a Biomedicina 24 assevera:

"É proibida toda a forma de discriminação contra uma pessoa em virtude de seu patrimônio genético".

- os vários distúrbios emocionais que podem surgir no portador de um diagnóstico pré-sintomático e no seu grupo familiar, gerando a necessidade de uma abordagem "psicossocial" das afecções genéticas. 16 Um destes distúrbios é a vivência antecipada e precoce da doença (transmissibilidade biológica), influenciada por uma concepção determinista, antes do seu início propriamente dito (transmissibilidade genética), 16 transformando uma pessoa saudável em uma pessoa doente 5 ou um risco genético subjetivo na própria enfermidade. 16 Outro é a inexistência de tratamento ou medida preventiva eficaz, 12 fazendo com que o indivíduo adote medidas radicais, como não ter filhos ou interromper uma gravidez; 7

- a importância da precaução, da prudência, da sabedoria 14 e de uma moral autógena reguladora para lidar com o risco das intervenções sobre o genoma humano; 6

- a aplicação do princípio da dignidade ao genoma humano. Essa dignidade, respeitadora do caráter único e da diversidade dos indivíduos, os impede de serem reduzidos às suas características genéticas e, posteriormente, discriminados, 11 e de serem instrumentalizados ou distinguidos em dignos ou não de viver;21

- a complexidade da informação ou desinformação gênica e o melhor uso que delas se possa fazer. Virtualmente ninguém, inclusive a maioria dos médicos, possui o conhecimento pleno, seguro e necessário para a discussão de todos os aspectos gerais e específicos da genética, ${ }^{19}$ o que torna a educação e, consequentemente, o aconselhamento genético pré e pós-teste, temas imprescindíveis; ${ }^{4}$

- a necessidade de consentimento livre, informado e esclarecido, por parte de um paciente, à investigação, ao diagnóstico e ao tratamento présintomáticos; 11

- em relação à terapia gênica:

- é moralmente aceitável promover modificações no genoma humano?2

- que magnitude deve ter o mal que se quer abordar e quem assim o determina para autorizar que se alterem as bases genéticas que acompanharam a humanidade durante milhões de anos?2

- alterações produtoras de certo tipo de enfermidades são, simultaneamente, evitadoras de outras, como por exemplo, a anemia falciforme protegendo da malária; 2

- as mutações espontâneas incontroláveis que sofrem, muitas vezes, os processos naturais. Esta "imperfeição" gênica compõe a hereditariedade humana, sendo fonte dos "erros" inevitáveis, da diversidade e de parte daquilo que nos faz humanos. ${ }^{2}$ - em relação aos testes genéticos propriamente ditos:

- têm suas limitações em cada situação, devendo ser usados apenas após demonstração de sua utilidade clínica e sob indicação e supervisão médica individualizada, respeitando-se os princípios da beneficência e da não-maleficência; 25

- obrigam-se a ter qualidade e serem de confiança para não induzirem o público em erro, produzindo consequências devastadoras; 25

- interesses comerciais podem criar publicidade enganosa ao prometerem resultados e conclusões que nunca poderão fornecer; 25

- a sua prática deve ser cuidadosamente regulamentada, ${ }^{1}$ sendo indispensável a aproximação e a cooperação entre as agências reguladoras internacionais. 25

\section{Considerações finais}

A investigação e a prática biotecnocientífica em relação ao genoma humano podem ser estimuladas e compartilhadas, como fontes de progresso, entretanto, devem receber, como tudo na vida, suas limitações éticas, morais, legais e sociais, com responsabilidade e consequência. No que tange a estes limites, pergunta-se: qual a sua extensão? Quem os determina? Em base a que parâmetros? Qual a sua formatação? ${ }^{11}$

O debate amplo e democrático de diversos segmentos da sociedade11 e a busca de um ou de alguns critérios éticos universais e consensuais capazes de incluir e ordenar os diferentes pontos de vista morais, ${ }^{14}$ dirimindo eventuais conflitos ou incompatibilidades radicais, ${ }^{6}$ possibilitam abordar essas questões, determinando sua justa moderação.

O que se suspeita é que as gerações futuras nos cobrarão os resultados de nossas ações presentes, potencialmente irreversíveis e irreparáveis, o que faz do respeito às liberdades fundamentais, aos direitos humanos e à dignidade ontológica princípio basilar. ${ }^{11}$ Parafraseando Silva, ${ }^{3}$ não devemos olhar para Deus como uma meta a ser alcançada, mas sim como o "ideal" regulador de nossas fronteiras. 


\section{Referências}

1. Pena SDJ, Azevedo ES. O projeto genoma humano e a medicina preditiva: avanços técnicos e dilemas éticos. In: Costa SIF, Garrafa V, Oselka G, organizadores. Iniciação à bioética. Brasília: CFM; 1998. p. 139-56.

2. Martínez SM. ¿Quién es el dueño del genoma humano? Rev Bioética. 1997; 5: 221-30.

3. Silva FL. O biofilho. Rev Bioética. 1997; 5: 185-93.

4. Matte U, Goldim JR. Desafios éticos do diagnóstico preditivo. [online]. 1998 [acesso em 29 jun 2009]. Disponível em: http://www.ufrgs.br/bioetica/prediti.htm

5. Nascimento JO. Medicina preditiva: seus aspectos positivos e negativos em face do direito à privacidade. Âmbito Jurídico. [periódico online]. 2008 set. [acesso em 29 jun 2009]. 57. Disponível em: http://www.ambitojuridico. com.br/site/index.php?n_link=revista_artigos_leitura\&artig o_id=3122

6. Garrafa V. O diagnóstico antecipado de doenças genéticas e a ética. Mundo Saúde (1995). 2000; 24: 424-8.

7. França GV. A velha e a nova ética médica. Rev AMRIGS 2006; 50: 244-8

8. Ferreira $\mathrm{ABH}$. Novo dicionário Aurélio da língua portuguesa. 3 ed. Curitiba: Positivo; 2004. 2120 p.

9. Salzano FM. Genética e ambiente. Rev Bioética. 1997; 5: 165-72.

10. Penchaszadeh VB. Problemas éticos do determinismo genético. Rev Bioética. 2004; 12: 61-8.

11. Bergel SD. Bioética, genética y derechos humanos: la declaración de la Unesco. Rev Bioética. [periódico online]. 1999 [acesso em 21 jul 2009]. 7 (2). Disponível em http://www.portalmedico.org.br/revista/bio2v7/launesco.ht

12. Sociedade Brasileira de Genética Clínica. Testes preditivos [online]. 2007 [acesso em 29 jun 2009]. Disponível em: http://www.projetodiretrizes.org.br/projeto_diretrizes/091.p df

13. Frota-Pessoa O. Fronteiras do biopoder. Rev Bioética 1997; 5: 253-61.

14. Schramm FR. Eugenia, eugenética e o espectro do eugenismo: considerações atuais sobre biotecnociência e bioética. Rev Bioética. 1997; 5: 203-20.
15. Clotet J. Bioética como ética aplicada e genética. Rev Bioética. 1997; 5: 173-83.

16. Zagalo-Cardoso JA, Rolim L. Aspectos psicossociais da medicina preditiva: revisão da literatura sobre testes de riscos genéticos. Psicol, Saúde Doenças. 2005; 6: 3-34.

17. Azevêdo ES. Terapia gênica. Rev Bioética. 1997; 5: 15764

18. Oliveira F. Uma visão feminista sobre os megaprojetos da genética humana (PGH e PDGH). Rev Bioética. 1997; 5: 263-72.

19. Opitz JM. O que é normal considerado no contexto da genetização da civilização ocidental? Rev Bioética. 1997; 5: 131-43.

20. Passos-Bueno MR. O projeto genoma humano. Rev Bioética. 1997; 5: 145-55.

21. Campos CLC. Risco de uma nova forma de eugenia em face do conhecimento do patrimônio genético humano. Parlatorium. [periódico online]. 2008 jan./jul. [acesso em 29 jun 2009]. 1. Disponível em: http://www.faminasbh. edu.br/revistaeletronica/download/ar1.pdf

22. Jonas H. Engenharia biológica - uma previsão. In: Jonas H. Ética, medicina e técnica. Lisboa: Vega; 1994. p. 63-116.

23. Torres JM. Resolviendo problemas bioéticos originados em el teste y screening genético para enfermedades recesivas. Rev Bioética. 1997; 5: 195-201.

24. Conselho da Europa. Convenção sobre os direitos do homem e a biomedicina. [online]. 1997 [acesso em 29 jun 2009]. Disponível em: http://www.gddc.pt/direitoshumanos/textos-internacionais-dh/tidhregionais/ convbiologiaNOVO.html

25. Portugal. Conselho Nacional de Ética para as Ciências da Vida. Parecer sobre venda directa de testes genéticos ao público. [online]. 2008 jul. [acesso em 29 jun 2009]. Disponível em: http://www.cnecv.gov.pt/NR/rdonlyres/...51E5.../p_056CNECV.pdf

Recebido em 30 de junho de 2010

Versão final apresentada em 22 de julho de 2010

Aprovado em 20 de setembro de 2010 